\title{
Mechanical Behavior of Hot-Mix Asphalt Made with Recycled Concrete Aggregates from Construction and Demolition Waste: A Design of Experiments Approach
}

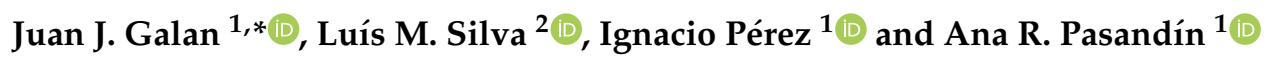 \\ 1 University of A Coruña, ETSI Caminos, Canales y Puertos, Campus de Elviña s/n, 15071 La Coruña, Spain \\ 2 CIETI, ISEP-School of Engineering, Polytechnic of Porto, Rua Dr. António Bernardino de Almeida 431, \\ 4200-072 Porto, Portugal \\ * Correspondence: jgalan@udc.es
}

Received: 12 June 2019; Accepted: 5 July 2019; Published: 8 July 2019

\begin{abstract}
The present work is a re-evaluation of previous research on the durability of hot-mix asphalt made with recycled concrete aggregates from construction and demolition waste (CDW) with a different approach. Response surface methodology (RSM) was used to conduct this study. The kind of natural aggregates (schist and calcite-dolomite), the recycled concrete aggregates percentage $(0 \%$, $20 \%, 40 \%$ and $60 \%$ ) and the water saturation $(0 \%$ and $100 \%)$ were the pertinent factors for this methodology. Indirect tensile stress (ITS) was determined in mixtures fabricated with $0 \%, 20 \%, 40 \%$ and $60 \%$ recycled concrete aggregates. According to the results, the ITS of the bituminous mixtures increases as the percentage of recycled concrete aggregate increases. This behavior is more significant when calcite-dolomite is used as a natural aggregate. Water saturation has the same influence in both natural aggregates. The indirect tensile strength ratio (ITSR) was calculated to evaluate the stripping potential. According to the Spanish specifications, the results suggest that the percentage of CDW that can be used for hot mixes is $17 \%$ when schist is used as natural aggregate and $14 \%$ for calcite-dolomite.
\end{abstract}

Keywords: recycled concrete aggregate; construction and demolition waste; indirect tensile stress; hot-mix asphalt; response surface methodology

\section{Introduction}

Construction materials surround our lives, it would be unthinkable to put them aside; buildings, roads and bridges among others are made of them. Beside of this, the construction activities play an important role in the economic development of the countries. Nevertheless, construction itself has a negative influence on the environment. It takes around $50 \%$ of raw material from nature; about $40 \%$ of total energy is consumed in its own procedures and produces $50 \%$ of total waste [1], but unfortunately, it seems that waste management is reaching a crisis point in all the world [2].

On the other hand, many of the European and the American roads are paved with hot-mix asphalt (HMA). As is well known, HMA is a combination of aggregates, the component in major portion (around 95\%), which are bounded by a derivative of petroleum so-called bitumen. In order to preserve our environment and save the natural resources, contributing with sustainable development and circular economy, in the last decades some waste materials have been used as aggregate in bituminous mixtures and thus, help solve the waste management of construction and demolition waste (CDW) [3]. In particular, CDW can be used in several applications as aggregate, for example in the manufacture of HMA $[4,5]$. According to the basis of the circular economy, the new paradigm of sustainability based 
on long-lasting design, maintenance and recycling [6,7], CDW would be able to use as a replacement of natural material as far as possible.

Nevertheless, the use of recycled concrete aggregates (RA) from CDW in the manufacture of HMA presents some drawbacks. One of the main disadvantages of RA is its tendency to absorb water because of the attached old cement mortar onto its surface, which is very difficult to remove. For that purpose, the RA can be pre-soaking with strong acids like $\mathrm{HCl}, \mathrm{H}_{2} \mathrm{SO}_{4}$ or $\mathrm{H}_{3} \mathrm{PO}_{4}$ [8], but although it improves the water absorption, the toxicity of this chemicals is a new problem to cope with. In addition, it must be taken into account that in some parts of the planet the deterioration of the pavements can be accelerated due to climate change [9].

In addition, the infiltration of water is one of the main causes of deterioration of HMA [10]. Moisture damage appears when a film of water infiltrates in the mix causing the loss of bond between the mastic and the aggregates. Water weakens the mastic by permeation also, leading to a loss of cohesion. Moisture damage can cause stripping in HMA, which is one of the most important ways of failure of HMA. Both, the type of aggregate, the type of mastic or even the $\mathrm{pH}$ of the water are factors that can influence the occurrence of stripping in a bituminous mixture.

The response surface methodology (RSM) approach not only estimates the influence of each factor on the response, but also the interaction between them and eventually nonlinear terms that confer curvature to the response surface. For this purpose, an experimental set of runs is designed to achieve the maximum amount of information with the minimum number of experiments. RSM has been applied in the design of bituminous mixtures on many other occasions. In this regard, Haghshenas et al. used this technique to analyze the moisture damage resistance of stone matrix bitumen taking the passing sieve size $4.75 \mathrm{~mm}$, the bitumen content and the lime content as factors in the factorial design [11]. Chávez-Valencia et al. conducted research based on RSM to predict the performance of bitumen pavement and demonstrated the adequate correlation of the partial second-order model with field specimens [12]. Al Nassar et al. also used this statistical approach to successfully optimize the mix design of cold bitumen emulsion mixtures [13]. Hamzah et al. analyzed the mixing and test temperature on the adhesion failure of bituminous mixtures by means of the RSM approach [14].

In previous work, Pérez and Pasandín studied the stripping potential in HMA made with different RA percentages and two natural aggregates (schist and calcite dolomite) [5]. In the present paper, the same situation was studied using a new approach based upon the RSM.

The percentage of recycled concrete aggregate (RA), the percentage of water saturation of the specimens and the type of natural aggregate (NA) were the factors considered for this study.

\section{Goal and Scope Definition}

The aim of this work was to evaluate the influence of the percentage of recycled concrete aggregate $(\% \mathrm{RA})$, percentage of water saturation of the specimen (\%S) and type of natural aggregate (NA), as well as the interactions between them on the indirect tensile strength (ITS) of an HMA. An AC 22 base G was chosen for this purpose. According to the European nomenclature, in Spain an AC 22 base 50/70 G is an asphalt concrete mixture with a nominal maximum grain size of $22 \mathrm{~mm}$, used in base courses of road pavements, with 50/70 bitumen penetration and with a coarse gradation $(G)$. The stripping process was also studied considering the indirect tensile strength ratio (ITSR) values. The mixture AC22 base $G$ was chosen because the base layers have less strict requirements in the Spanish specification (PG-3) [15].

For this purpose, after conducting some laboratory tests, we used a composite factorial design in order to obtain a regression model that makes it possible to determine the optimum level of the parameters mentioned above. A wide range of RA percentages (from $0 \%$ to $100 \%$ ) was used in order to obtain an accurate model. This allows us to obtain the maximum RA percentage that should be used in the manufacture of the AC 22 base G, using the model equations, without the need of increasing the number of experiments. Therefore, the model significantly reduces the experimental work. 


\section{Materials and Methods}

\subsection{Materials}

\subsubsection{Natural Aggregates}

Schist (35\% of quartz) (NA1) and calcite dolomite (20\% of quartz) (NA2) were used as natural aggregates (NA). Two quarries supplied the two virgin aggregates in fractions of 0/6 $\mathrm{mm}, 6 / 12 \mathrm{~mm}$ and 12/25 mm. These aggregates complied with the Spanish specifications, as it was shown by Pérez et al. [5]. The bulk specific gravity for NA1 was between 2.76 and $2.68 \mathrm{~g} / \mathrm{cm}^{3}$ and for NA2 between 2.88 and $2.82 \mathrm{~g} / \mathrm{cm}^{3}$. The water absorption coefficient for NA1 ranged from $0.12 \%$ (fraction $12 / 25$ ) to $0.21 \%$ (fraction 6/12) and $0.55 \%$ (fraction $12 / 25$ ) to $0.82 \%$ (fraction $6 / 12$ ) for NA2.

\subsubsection{Recycled Aggregates (RA)}

Construction and demolition waste (CDW) were used as recycled concrete aggregate (RA).

The CDW was previously selected and crushed. The pollutants were removed. Then the CDW was sieved and finally washed. The entire process described above was carried out in the RA plant.

The RA plant produces fractions of $0 / 40 \mathrm{~mm}$, but in this research, only coarse RA greater than $4 \mathrm{~mm}$ was used for the HMA production [5]. The composition in percent by mass, provided by the RA plant, is indicated in Table 1 . The impurities were visually detected and handily removed in order to guarantee a better heterogeneity of the RA.

Table 1. Composition in percent by mass of Recycled Aggregate (RA).

\begin{tabular}{cc}
\hline Material & $\%$ \\
\hline Concrete & 72.5 \\
Stone & 21.5 \\
Miscellaneous Bituminous & 4 \\
Ceramic materials & 1 \\
Stone impurities (clay, metals, wood, rubber and gypsum plaster) & 1 \\
\hline
\end{tabular}

The flakiness index, 34\%, and sand equivalent, $67 \%$, values meet the requirements stipulated in the Spanish specifications [5]. It is important to notice that the RA does not comply with the Los Angeles fragmentation coefficient specification. After the test, the value obtained for this parameter was higher than $34 \%$. The maximum accepted value for Los Angeles coefficient in the Spanish specifications is $30 \%$.

In addition, the water absorption coefficient value is around $6 \%$, which was much higher than that of NA1 and NA2. It can be explained taking into account the presence of cement mortar from the concrete within the RA.

According to the X-ray fluorescence technique and as can be seen in Figure 1, $\mathrm{SiO}_{2}$ is the most relevant chemical component, around $60 \%$ in fractions for $8 / 11.2$ and $10 / 14 \mathrm{~mm}$ and around $50 \%$ in the fraction of $0 / 2 \mathrm{~mm}$. The percentage of $\mathrm{CaO}$ is around $20 \%$ for all fractions. In other words, the recycled concrete aggregate has a siliceous nature fundamentally; it means that a poor adhesiveness can be expected. In Figure 1 represents just the main components, the rest of them are present in proportions lower than $1 \%$.

In this investigation, percentages of $0 \%, 20 \%, 40 \%, 60 \%, 80 \%$ and $100 \%$ RA were initially considered. However, as the laboratory evaluation was being conducted, the percentages of $80 \%$ and $100 \%$ were discarded due to the weakness of the mixtures made with these high percentages that made that during the compaction of the samples, some particles were detached. 


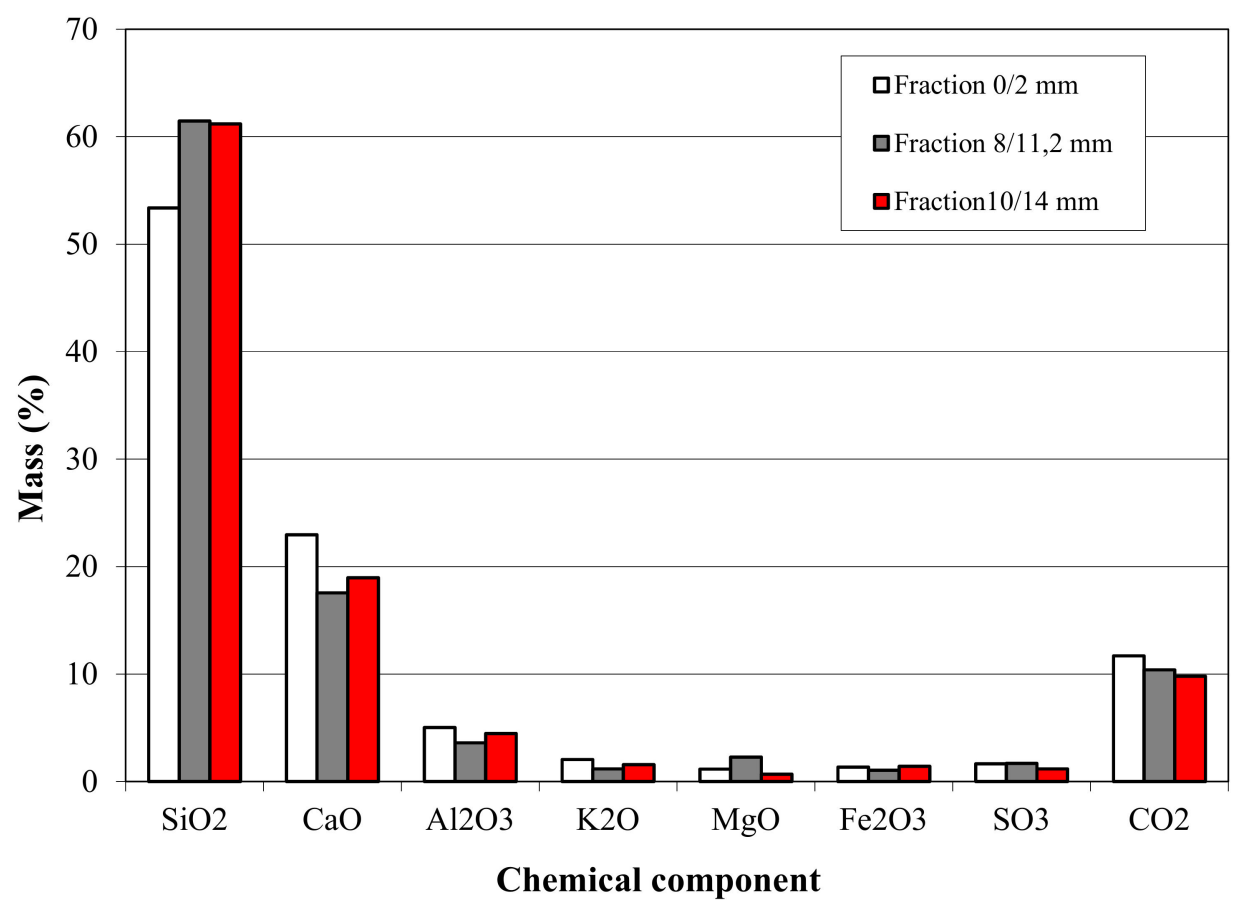

Figure 1. Chemical composition of the RA used in this investigation.

\subsubsection{Filler}

Portland cement was used as filler in all the mixtures. The Blaine surface area was $3350 \mathrm{~cm}^{2} \mathrm{~g}^{-1}$ and the specific gravity, $3.12 \mathrm{gcm}^{-3}$ and Pfeiffer's penetration index had a value of -0.8 with a density of $1.03 \mathrm{gcm}^{-3}$.

\subsubsection{Bitumen}

The binder used complied with all the Spanish specifications (B50/70). It had a penetration grading of $69 \times 10^{-1} \mathrm{~mm}$ and a softening point with the ring and ball method equal to $48.5^{\circ} \mathrm{C}$.

\subsection{Methodology}

\subsubsection{Mechanical Test}

Eight hot-mix asphalt type AC 22 base 50/70 G course mixtures were designed with the Marshall method performed according to the Spanish NLT-159 standard [16]. For each hot-mix asphalt type, five cylindrical samples compacted with 75 blows per side were made with different bitumen percentages. The RA coarsest fractions were used to manufacture the Marshal specimens to obtain the optimum bitumen content as it was detailed by Pérez et al. [5].

The eight hot-mix asphalt type AC 22 base 50/70 G course mixtures were designed with the same gradation but different percentages of RA. Four mixtures were prepared using NA1 with $0 \%$ (control), $20 \%, 40 \%$ and $60 \%$ of RA and four other samples for NA2 with the same percentages of RA as in the previous case.

Afterward, eight AC 22 base 50/70 G course mixtures were manufactured, but this time with the Marshall optimum bitumen content selected previously. The EN-12697 [17] was followed to analyze the stripping potential of the HMA.

This standard specifies that a minimum of six samples should be tested. The samples were subdivided into two subsets with three specimens in each subset. The "dry" subset was kept at room temperature, while the "wet" subset was saturated and was held in a water bath for 3 days at $40{ }^{\circ} \mathrm{C}$. After that time, the specimens of each subset were left for a minimum of $2 \mathrm{~h}$ at $15^{\circ} \mathrm{C}$ : the "dry" subset in air and the "wet" subset in water. The tensile strength of the two subsets was then 
determined. Cylindrical specimens were compacted with 50 blows on each side. Figure 2 shows the equipment used.

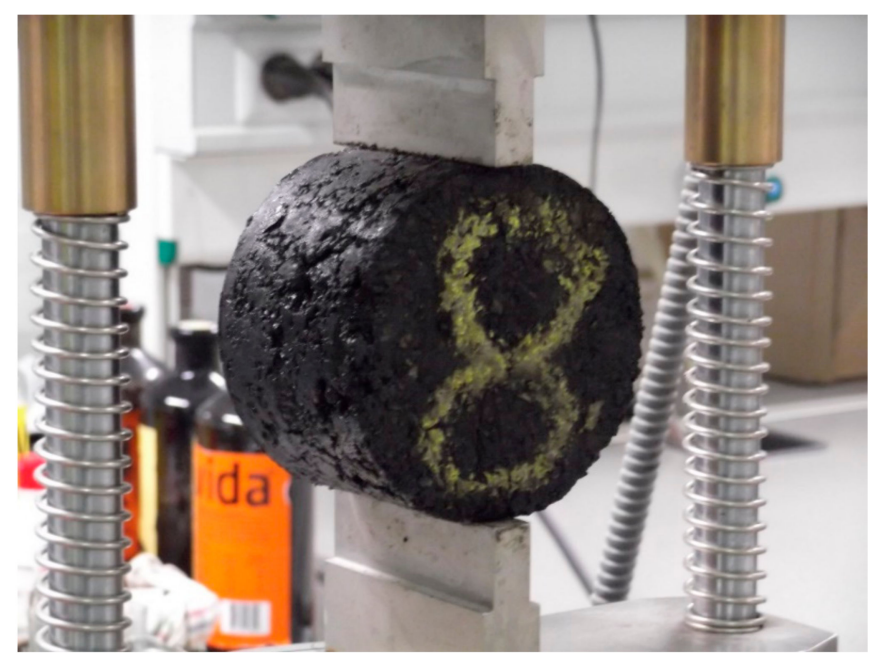

Figure 2. Indirect tensile test (ITS).

In each AC 22 base, 50/70 G course mixture was evaluated their moisture damage resistance (stripping potential) by means of the indirect tensile strength ratio (ITSR). It was calculated in compliance with the European standard EN-12697-12 [17]. ITSR is defined by Equation (1):

$$
I T S R=\frac{I T S_{w}}{I T S_{D}} \times 100
$$

where ITS $\mathrm{W}_{\mathrm{w}}$ is the indirect tensile strength $(\mathrm{MPa})$ of the wet samples and $\mathrm{ITS}_{\mathrm{D}}$ is the indirect tensile strength (MPa) of the dry samples. The ITSR provides information about the loss of cohesion of the mixture because of the action of the water within the specimen. The ITS test was performed according to the European standard EN-12697-23 [18].

\subsubsection{Response Surface Methodology}

Response surface methodology can be defined as a collection of mathematical and statistical techniques to analyze situations in which a response is influenced by several variables [19]. For that purpose, a regression model for three factors is set in which the response is a linear combination of the factors, interactions and quadratic terms in the following way:

$$
y=\beta_{0}+\sum_{j=1}^{k} \beta_{j} x_{j}+\sum_{j=1}^{k} \beta_{j j} x_{j}^{2}+\sum_{i=1} \sum_{j>1}^{k} \beta_{i j} x_{i} x_{j}+\beta_{i j l} x_{i} x_{j} x_{l}
$$

where $\mathrm{y}$ is the response, $\mathrm{xj}$ are the factors, $\beta_{j}, \beta_{i j}$ and $\beta_{j j}$ are the regression coefficients of, respectively, factors, interactions and quadratic terms, $k$ is the number of the variables or factors included in the factorial design.

The quality of the regression was evaluated by testing the significance of the model and its lack-of-fit and by measuring $R^{2}$. This value quantifies how much variability of the total observed response values can be explained by the model [20].

As said before, the variables chosen in this study were the RA percentage (\%RA), the percentage of water saturation, $(\% \mathrm{~S})$, and the type of natural aggregate (NA). As can be seen in Table 2 , the percentages of recycled concrete aggregate are in the range of $0 \%$ to $60 \%$ spaced between them by $20 \%$, the percentage of water saturation can only take two values $0 \%$ or $100 \%$ (totally dry or totally saturated) and the natural aggregate is characterized by the percentage of quartz (NA1, 35\%; NA2, 20\%). 
Table 2. Variables coded levels.

\begin{tabular}{cccc}
\hline Factor & $x_{i}$ & Original Value & Code Level \\
\hline \multirow{2}{*}{$\%$ RA } & $x_{1}$ & 0 & -1 \\
& & 40 & $-1 / 3$ \\
& & 60 & $+1 / 3$ \\
$\% \mathrm{~S}$ & $x_{2}$ & 0 & +1 \\
\hline \multirow{2}{*}{$\mathrm{NA}$} & $x_{3}$ & 100 & -1 \\
& & 20 & +1 \\
\hline
\end{tabular}

Each one of the variables was coded in the following way: the code +1 corresponds to the highest real value of the variable and -1 represents the lowest.

In the case of the percentage of RA, the codes $+1 / 3$ and $-1 / 3$ depict the intermediate levels of this variable, that is, $40 \%$ and $20 \%$ respectively.

Table 2 summarizes the above.

\section{Results and Discussion}

\subsection{Indirect Tensile Strength (ITS)}

A total of 16 combinations of levels have been studied; 4 levels of $\%$ RA $\times 2$ levels of $\% \mathrm{~S} \times 2$ levels of NA. In order to predict the variance of pure error three replicates were conducted for each combination. Table 3 shows the results of the ITS and the ITSR for each sample studied. Furthermore, voids in mineral aggregates (VMA), air voids (Va) and voids filled with bitumen (VFB) have been included in it. Spanish PG-3 requirements are the following: voids in mineral aggregates must be greater or equal to $14 \%$, air voids between $5 \%$ and $9 \%$ and no specification for voids filled with bitumen [15]. All the results for these parameters are in perfect compliance with the previous values.

Table 3. ITS wet (ITSw) and dry (ITSD) results (MPa), ITSR, VMA, Va, VFB.

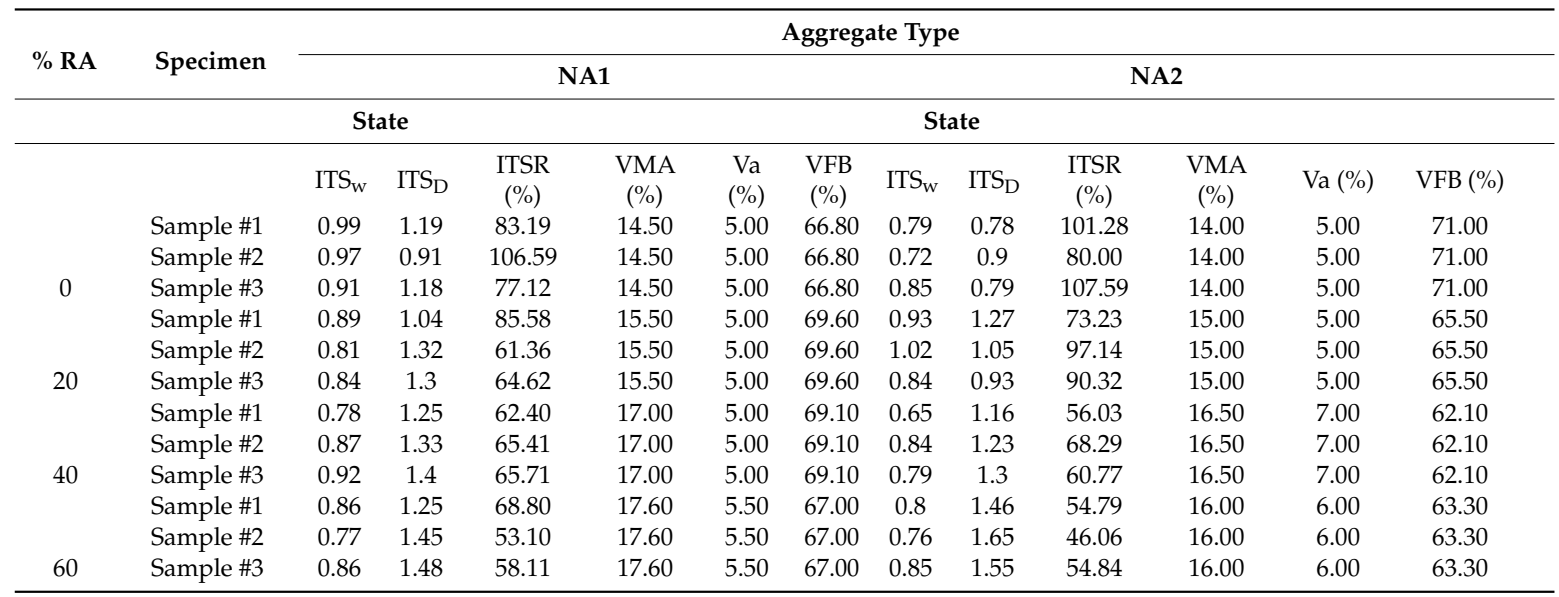

It was observed that the mixing times of the RA with the bitumen until reaching a coating of $100 \%$ are, at least, on the order of 1.5 times the mixing times required by the natural aggregates analyzed. In addition, the presence of RA makes the compaction of the hot bituminous mixtures more difficult. It is due to the greater roughness of the cement mortar adhered to the RA increases the internal friction between aggregate particles. Moreover, this difficult to compact the samples can be observed in Table 3; when the VMA and Va voids tend to increase when the percentage of RA grows. This behavior is 
more prominent when the NA2 is used as the aggregate. Table 3 also shows the ITS of the wet and dry samples (State).

Student's $t$-test was used to test individual regression coefficients on the proposed model (equation 2). According to this test, either the interaction between the percentage of water saturation and percentage of natural aggregate or the second order term related with recycled concrete aggregate is not statistically significant in the response of indirect tensile stress (ITS) of the specimen. Table 4 shows the statistical $t$-test results where $\mathrm{H}_{0}$ states that $\beta_{j}=0$ in a bilateral test. In Table 4 "No" means that the null hypothesis must be rejected with a confidence level of $95 \%$ while "Yes" means the opposite.

Table 4. Student's t-test on individual regression coefficients.

\begin{tabular}{cccccc}
\hline$x_{\boldsymbol{i}}$ & $\boldsymbol{\beta}_{\boldsymbol{i}}$ & Standard Error & $\boldsymbol{t}$-test & $\boldsymbol{p}$-Value & $\mathrm{H}_{\mathbf{0}}$ \\
\hline Independent & +1.032 & $2.29 \times 10^{-2}$ & +44.97 & $3.22 \times 10^{-35}$ & No \\
$x_{1}$ & $+1.07 \times 10^{-1}$ & $1.92 \times 10^{-2}$ & +5.56 & $2.09 \times 10^{-6}$ & No \\
$x_{2}$ & $1.85 \times 10^{-1}$ & $1.43 \times 10^{-2}$ & 12.88 & $1.26 \times 10^{-15}$ & No \\
$x_{3}$ & $+3.46 \times 10^{-2}$ & $1.43 \times 10^{-2}$ & +2.41 & $2.06 \times 10^{-2}$ & No \\
$x_{1} x_{2}$ & $1.44 \times 10^{-1}$ & $1.92 \times 10^{-2}$ & 7.47 & $4.83 \times 10^{-2}$ & No \\
$x_{1} x_{3}$ & $5.93 \times 10^{-2}$ & $1.92 \times 10^{-2}$ & 3.08 & $3.78 \times 10^{-3}$ & No \\
$x_{2} x_{3}$ & $8.33 \times 10^{-3}$ & $1.43 \times 10^{-2}$ & $5.81 \times 10^{-1}$ & $5.64 \times 10^{-1}$ & Yes \\
$x_{1} x_{2} x_{3}$ & $+4.05 \times 10^{-2}$ & $1.92 \times 10^{-2}$ & +2.11 & $4.17 \times 10^{-2}$ & No \\
$x_{12}$ & $-1.87 \times 10^{-3}$ & $3.23 \times 10^{-2}$ & $-5.81 \times 10^{-2}$ & $9.54 \times 10^{-1}$ & Yes \\
\hline
\end{tabular}

Therefore, discarding the coefficients with no statistical significance from the full model and recalculating the regression coefficients based on the original variables, the ITS equation can be written as follows:

$$
\begin{aligned}
\text { ITS }= & 6.21 \times 10^{-1}+1.67 \times 10^{-2} x_{1}-8.17 \times 10^{-4} x_{2}+1.25 \times 10^{-2} x_{3}- \\
& 1.18 \times 10^{-4} x_{1} x_{2}-3.04 \times 10^{-4} x_{1} x_{3}+8.10 \times 10^{-7} x_{1} x_{2} x_{3} .
\end{aligned}
$$

Table 5 summarizes the analysis of variance of the least squares problem. As can be seen, the $p$-value associated with the regression $\mathrm{F}_{0}$, the model is significant, i.e., there is at least one $\beta_{j}$ which is different from zero. In addition, the $\mathrm{R}^{2}$ is 0.86 which indicates that $14 \%$ of the total response variance is due to unexplained reasons.

Table 5. Analysis of variance and lack of fit test.

\begin{tabular}{cccccc}
\hline $\begin{array}{c}\text { Source of } \\
\text { Variation }\end{array}$ & $\begin{array}{c}\text { Sum of } \\
\text { Squares }\end{array}$ & $\begin{array}{c}\text { Degrees of } \\
\text { Freedom }\end{array}$ & Mean Square & $\mathbf{F}_{\mathbf{0}}$ & $\boldsymbol{p}$-Value \\
\hline Regression & 2.649 & 6 & 0.4415 & 42.53 & $4.5 \times 10^{-16}$ \\
Residual & 0.4256 & 41 & 0.01038 & & \\
Lack of fit & 0.1173 & 9 & 0.01303 & 1.352 & 0.250 \\
Pure error & 0.3083 & 32 & 0.009635 & & \\
Total & 3.075 & 47 & & & \\
\hline
\end{tabular}

The sum of squares due to lack of fit and pure error is also included in the same table. With these variance terms, a lack of fit test was performed and concluded that there is no evidence that the regression model does not fit adequately.

Taking into account that $x_{3}$ corresponds to the type of natural aggregate characterized by its quartz content, the expressions of ITS for schist and calcite dolomite aggregates are, respectively, the following:

$$
\begin{aligned}
& \text { NA1 }: \text { ITS }=1.06+6.08 \times 10^{-3} x_{1}-8.17 \times 10^{-4} x_{2}-8.98 \times 10^{-5} x_{1} x_{2} \\
& N A 2: \text { ITS }=0.87+1.06 \times 10^{-2} x_{1}-8.17 \times 10^{-4} x_{2}-1.02 \times 10^{-4} x_{1} x_{2} .
\end{aligned}
$$


A residual analysis was carried out to test the goodness of fit and by this way verify the suitability of the regression models of both natural aggregates. In Figures 3 and 4, the expected residuals ranked by the rankit method against the observed ones assuming normal distribution with the same mean and variance of the latter are plotted for schist and calcite dolomite aggregates, respectively. It can be observed that the residues are normally distributed throughout the observed responses, which confirms the validity of the fit.

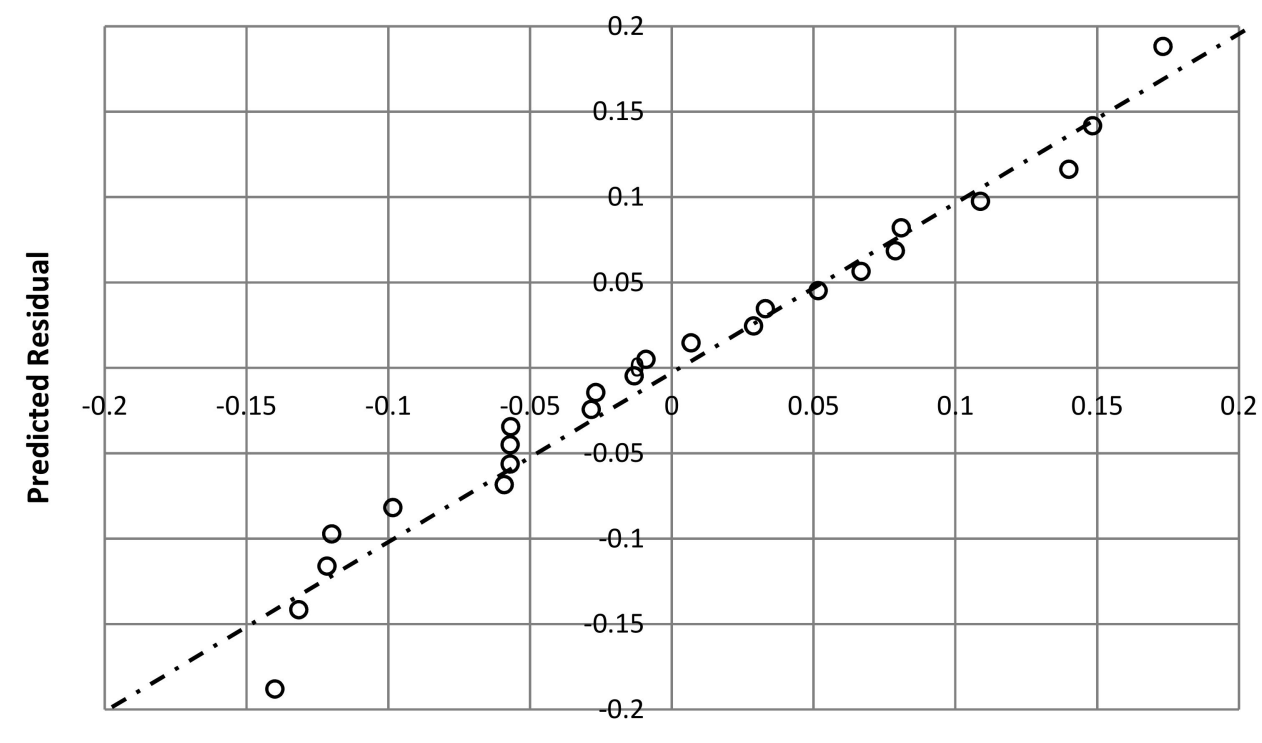

Observed Residual

Figure 3. Normal predicted versus observed residuals for NA1.

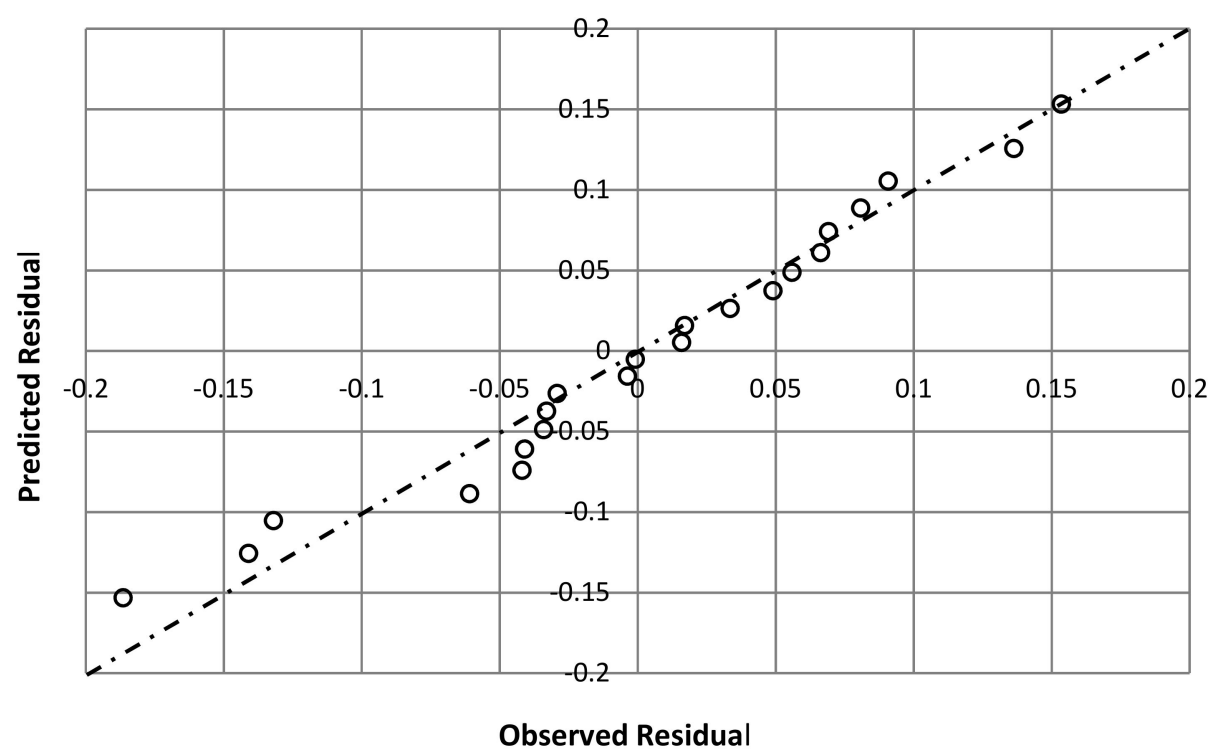

Figure 4. Normal predicted versus observed residuals for NA2.

Figures 5 and 6 show the response surface model and the experimental data for NA1 and NA2 respectively. As was expected, the ITS of the NA1 is greater than that of the NA2. It is because of the siliceous nature of RA and NA1. Besides that, in both cases, the influence of the percentage of recycled concrete material upon the indirect tensile strength of the dry samples results positively. The model indicates that when calcite is used as natural aggregate the influence of RA is higher than in schist one. Then, as was also expected, the addition of RA favored more the weaker natural aggregate. In general, the positive effect of RA upon the ITS can be explained as a result of the roughness of the RA surface 
that increases the internal friction of the mixture. Summarizing, the higher the percentage of RA is, the higher the ITS is. That is, RA improves the mechanical properties of the mixture when used in percentages up to $60 \%$.

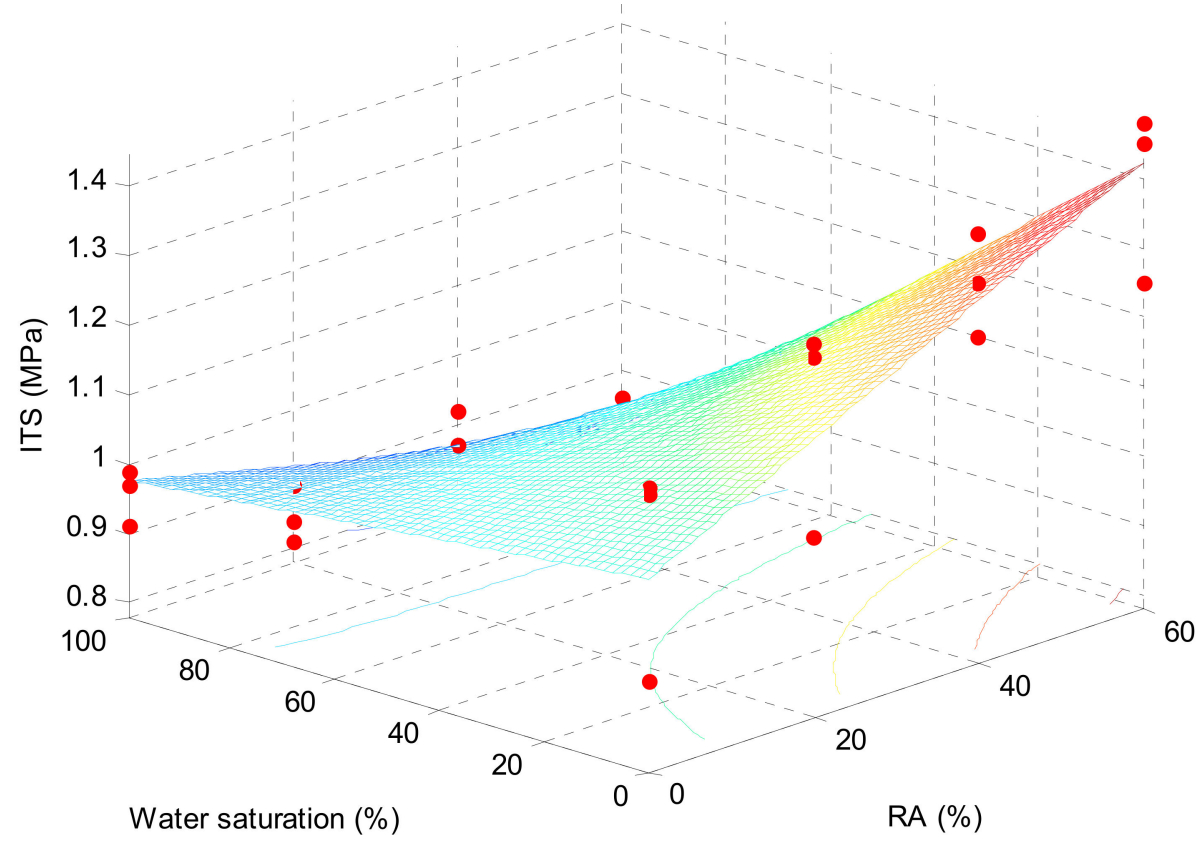

Figure 5. ITS response surface for NA1.

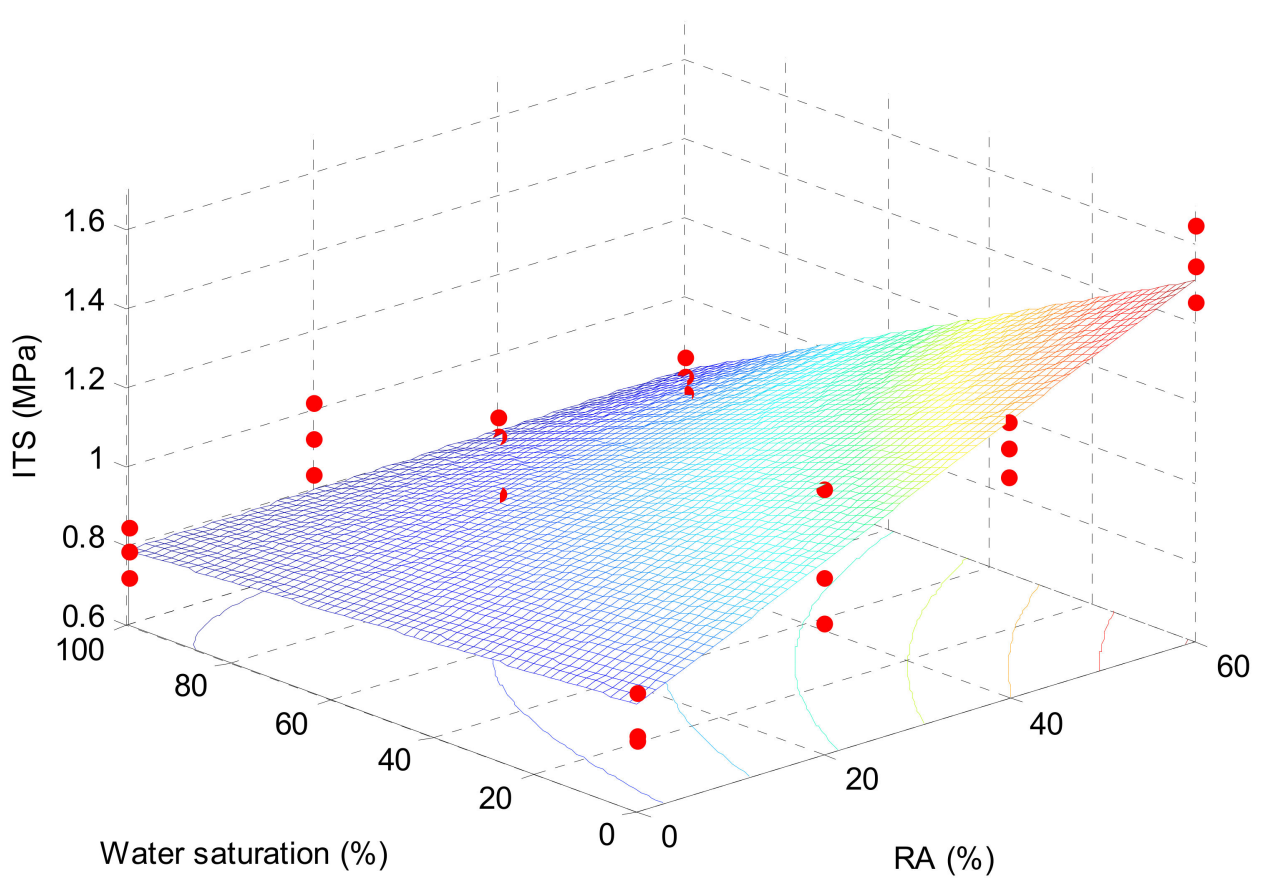

Figure 6. ITS response surface for NA2.

The influence of the percentage of water saturation is the same for both cases, having a negative impact on the response. It was also an expected result; water could lead to the dissolution of some compounds of the RA, thus if humidity increases, the tensile strength goes down. The loss of adhesion between bitumen and the aggregates due to the presence of water can be explained thermodynamically. 
The adsorption process between water and aggregates are more favorable in terms of Gibbs free energy than between bitumen and aggregates [21].

The interaction between RA and water affects less NA1, that has more percentage of quartz than NA2. This result could mean that the adsorption energy between the components of the mixture is higher in the case of NA1 than in that of NA2, which has less quantity of quartz. In order to establish this hypothesis, measures of surface energy $(\gamma)$ both in bitumen and aggregates (natural and recycled) must be done. Beside of this, the moisture damage index (MDI) should be evaluated as the ratio between the total adhesive bond energy for the dry and wet sample [22]. In addition, the siliceous nature of RA has a higher influence in the mixtures made with NA2 than in the mixtures made with NA1, because schist has a siliceous nature too, which reinforces the hydrophilic behavior of the mix [23].

\subsection{Indirect Tensile Strength Ratio (ITSR)}

According to the $t$-test, as shown in Table 6, for the ITSR, only the percentage of RA is significant in the model.

Table 6. Student's t-test on individual regression coefficients.

\begin{tabular}{cccccc}
\hline Variables & $\boldsymbol{\beta}_{\boldsymbol{j}}$ & Standard Error & $\boldsymbol{t}$-Test & $\boldsymbol{p}$-Value & $\mathbf{H}_{\mathbf{0}}$ \\
\hline Independent & 70.49 & 3.39 & 20.74 & $1.65 \times 10^{-14}$ & No \\
$x_{1}$ & -18.85 & 2.85 & -6.62 & $2.49 \times 10^{-6}$ & No \\
$x_{3}$ & -1.60 & 2.12 & $-7.53 \times 10^{-1}$ & $4.61 \times 10^{-1}$ & yes \\
$x_{1} x_{3}$ & 4.91 & 2.85 & 1.72 & $1.01 \times 10^{-1}$ & yes \\
$x_{12}$ & 3.81 & 4.78 & $7.97 \times 10^{-1}$ & $4.35 \times 10^{-1}$ & yes \\
\hline
\end{tabular}

Where $\beta_{j}$ are the coefficients of the coded variables and $\mathrm{H}_{0}$ represents the null hypothesis.

From the values of Table 6, the relationship between ITSR and the percentage of RA has a decreasing behavior. The penetration of water in a bitumen film is not an easy problem to explain. Several mechanisms were proposed such as spontaneous emulsification due to an inverted emulsion $\mathrm{W} / \mathrm{O}$; pore pressure, because of the presence of water in the structure of the pore of the mixture and the aggregate characteristics. [24].

Taking into account the last mechanism, the recycled material used in this research behaved as a hydrophilic material because of the high amount of silica in it. Therefore, the capacity of the water to displace the bitumen in the mixture is the main cause of stripping of the mixture in this case.

According to Equations (1) and (4), the maximum RA percentage to achieve an ITSR equal or higher than $80 \%$ (minimum required by the Spanish specifications) is $16.8 \%$ in the case of mixtures made with schist as natural aggregate. Similarly, in the case of mixtures made with calcite dolomite as natural aggregate, the maximum RA percentage to achieve the minimum ITSR required by the Spanish specifications is $11.4 \%$.

The above percentages could be improved using several processes of transformation of RA to improve the behavior of the mixtures against water. Pasandin and Pérez cured in the oven the mixtures for $4 \mathrm{~h}$ after mixing and before compaction at $170{ }^{\circ} \mathrm{C}$. This methodology improved the stripping performance [25]. In addition, the same authors [26] proposed to pre-coat the recycled concrete aggregate with bitumen emulsion in order to improve the moisture damage resistance of mixtures made with RA. Lee et al. proposed to pre-coat the RA with a slag cement paste [27]. Zhu and Zhong coated the RA with a patented liquid silicone resin [28].

Another possibility is with surfactants as antistripping agents. Most of them are cationic, although anionic can be used in some circumstances. Recently, one of the authors published research about a cationic non-commercial surfactant that it could be used as anti-strip additive [29]. 


\section{Conclusions}

In this research, the stripping behavior of HMA, type AC 22 base $\mathrm{G}$ for base courses of road pavements, made with $0 \%, 20 \%, 40 \%$ and $60 \%$ of RA was analyzed. For this analysis, two types of natural aggregates were used: schist and calcite-dolomite. RSM methodology was used in order to analyze the ITS and the ITSR of such mixtures. The factors used in this study were the percentage of quartz in the natural aggregate, the water saturation and the percentage of RA. As a result, the following conclusions were drawn.

The model shows that there were interactions between the percentage of water saturation and the recycled concrete aggregate. Although quadratic terms were considered, they were disregarded when $t$-test for the significance of individual terms was undertaken.

According to this approach, the use of RA in percentages up to $60 \%$ improves the mechanical behavior of the mix. Moreover, it is more significant in ITS results when samples made with NA2

The percentage of water saturation had the same influence on the ITS results for both natural aggregates. The high water absorption coefficient, around $6 \%$, of RA overshadowed the influence of the natural aggregate.

The joint influence of the percentage of water saturation and RA percentage on the ITS results is higher in NA2; it means that the interfacial bond energy is higher in NA1 because of the quartz influence.

ITSR decreases are directly proportional to the percentage of RA. The rest of the interactions are not significant according to $t$-test for the significance of individual terms.

Taking into account the Spanish specifications for ITSR, around $17 \%$ is the maximum RA percentage for mixtures made with schist as natural aggregate and around $11 \%$ for calcite dolomite ones.

\section{Further Researches}

Using several cationic surfactants as an anti-stripping agent and estimate the superficial free energy of the HMA, both wet and dry ones in order to obtain the indirect tensile strength ratio (ITSR) for moisture damage assessment.

Author Contributions: Both I.P. and A.R.P. designed the laboratory study, L.M.S. software and J.J.G. analyzed the data and all of us wrote and revised the article.

Funding: This research received no external funding.

Conflicts of Interest: The authors declare no conflict of interest.

\section{References}

1. Oikonomou, N.D. Recycled concrete aggregates. Cement Concr. Compos. 2005, 27, 315-318. [CrossRef]

2. Saberian, M.; Li, J.; Nguyen, B.T.; Setunge, S. Estimating the resilient modulus of crushed recycled pavement materials containing crumb rubber using the Clegg impact value. Resour. Conserv. Recycl. 2019, 141, 301-307. [CrossRef]

3. Rao, A.; Jha, K.N.; Misra, S. Use of aggregates from recycled construction and demolition waste in concrete. Resour. Conserv. Recycl. 2007, 50, 71-81. [CrossRef]

4. Pereira, P.A.; Oliveira, J.R.; Picado-Santos, L.G. Mechanical Characterisation of Hot Mix Recycled Materials. Int. J. Pavement Eng. 2004, 5, 211-220. [CrossRef]

5. Pérez, I.P.; Pasandin, A.R.; Gallego, J. Stripping in hot mix asphalt produced by aggregates from construction and demolition waste. Waste Manag. Res. 2012, 30,3-11. [CrossRef]

6. Geissdoerfer, M.; Savaget, P.; Bocken, N.M.; Hultink, E.J. The Circular Economy-A new sustainability paradigm? J. Clean. Prod. 2017, 143, 757-768. [CrossRef]

7. Haas, W.; Krausmann, F.; Wiedenhofer, D.; Heinz, M. How Circular is the Global Economy? An Assessment of Material Flows, Waste Production, and Recycling in the European Union and the World in 2005. J. Ind. Ecol. 2015, 19, 765-777. [CrossRef]

8. Li, J.; Xiao, H.; Zhou, Y. Influence of coating recycled aggregate surface with pozzolanic powder on properties of recycled aggregate concrete. Constr. Build. Mater. 2009, 23, 1287-1291. [CrossRef] 
9. Guest, G.; Zhang, J.; Maadani, O.; Shirkhani, H. Incorporating the impacts of climate change into infrastructure life cycle assessments: A case study of pavement service life performance. J. Ind. Ecol. 2019, 1-13. [CrossRef]

10. Kiggundu, B.M.; Roberts, F.L. Stripping in HMA Mixtures: State-of-the-Art and Critical Review of Test Methods; National Center for Asphalt Technology-Auburn University: Auburn, AL, USA, 1988.

11. Haghshenas, H.; Khodaii, A.; Khedmati, M.; Tapkin, S. A mathematical model for predicting stripping potential of Hot Mix Asphalt. Constr. Build. Mater. 2015, 75, 488-495. [CrossRef]

12. Chávez-Valencia, L.; Manzano-Ramírez, A.; Luna-Barcenas, G.; Alonso-Guzmán, E. Modelling of the performance of asphalt pavement using response surface methodology. Build. Environ. 2005, 40, 1140-1149. [CrossRef]

13. Nassar, A.I.; Thom, N.; Parry, T. Optimizing the mix design of cold bitumen emulsion mixtures using response surface methodology. Constr. Build. Mater. 2016, 104, 216-229. [CrossRef]

14. Hamzah, M.O.; Teh, S.Y.; Golchin, B.; Voskuilen, J. Use of imaging technique and direct tensile test to evaluate moisture damage properties of warm mix asphalt using response surface method. Constr. Build. Mater. 2017, 132, 323-334. [CrossRef]

15. Dirección General de Carreteras. Pliego de Prescripciones Técnicas Generales Para Obras de Carreteras y Puentes PG-3; Ediciones Liteam; Dirección General de Carreteras: Madrid, Spain, 2002.

16. Ministerio de Obras Públicas y Transportes. NLT-159. Resistencia a la Deformación Plástica de Mezclas Bituminosas Empleando el Aparato Marshall, 2nd ed.; Ministerio de Obras Públicas y Transportes, Ensayos de carreteras: Madrid, Spain, 1992.

17. AENOR (Asociación Española de Normalización y Certificación). UNE-EN 12697-12 “Bituminous Mixtures. Test Methods for Hot Mix Asphalt. Determination of the Water Sensitivity of Bituminous Specimens"; AENOR: Madrid, Spain, 2006. (In Spanish)

18. AENOR (Asociación Española de Normalización y Certificación). UNE-EN 12697-23 "Bituminous mixtures. Test methods for hot mix asphalt. Determination of the indirect tensile strength of bitumen specimens"; AENOR: Madrid, Spain, 2006. (In Spanish)

19. Montgomery, D. Design and Analysis of Experiments, 8th ed.; John Wiley and Sons: London, UK, 2013; pp. 478-496.

20. Paíga, P.; Silva, L.M.S.; Delerue-Matos, C. Optimization of the Ion Source-Mass Spectrometry Parameters in Non-Steroidal Anti-Inflammatory and Analgesic Pharmaceuticals Analysis by a Design of Experiments Approach. J. Am. Soc. Mass Spectrom. 2016, 27, 1703-1714. [CrossRef] [PubMed]

21. Caro-Spinel, S.; Alvarez-Lugo, A.E. Assessment of moisture damage susceptibility of asphalt of hot-mix asphalt to moisture damage. Rev. Fac. Ing. Univ. Antioq. 2006, 1970, 2-13.

22. Bhasin, A.; Masad, E.; Little, D.; Lytton, R.; Information, R. Limits on Adhesive Bond Energy for Improved Resistance of Hot-Mix Asphalt to Moisture Damage. Transp. Res. Rec. 2006, 1970, 3-13. [CrossRef]

23. Taylor, M.A.; Khosla, N.P. Stripping of asphalt pavements: State of the art. Transp. Res. Rec. 1983, 911, 150-158.

24. Scott, J.A.N. Adhesion and disbonding mechanisms of asphalt used in highway construction and maintenance. Assoc. Asph. Paving Technol. Proc. 1978, 47, 19-48.

25. Pasandín, A.; Pérez, I.P.; Pasandín, A.M.R. Laboratory evaluation of hot-mix asphalt containing construction and demolition waste. Constr. Build. Mater. 2013, 43, 497-505. [CrossRef]

26. Pasandín, A.; Pérez, I.P.; Pasandín, A.M.R. Mechanical properties of hot-mix asphalt made with recycled concrete aggregates coated with bitumen emulsion. Constr. Build. Mater. 2014, 55, 350-358. [CrossRef]

27. Lee, C.-H.; Du, J.C.; Shen, D.H. Evaluation of pre-coated recycled concrete aggregate for hot mix asphalt. Constr. Build. Mater. 2012, 28,66-71. [CrossRef]

28. Zhu, J.; Wu, S.; Zhong, J.; Wang, D. Investigation of asphalt mixture containing demolition waste obtained from earthquake-damaged buildings. Constr. Build. Mater. 2012, 29, 466-475. [CrossRef]

29. Galan, J.J. Thermodynamic characterization of a non-commercial emulsifying agent for asphalt emulsion. Environ. Sci. Pollut. Res. 2018, 1-8. [CrossRef] [PubMed]

(C) 2019 by the authors. Licensee MDPI, Basel, Switzerland. This article is an open access article distributed under the terms and conditions of the Creative Commons Attribution (CC BY) license (http://creativecommons.org/licenses/by/4.0/). 